\title{
OUTCOME OF ERCP (ENDOSCOPIC RETROGRADE CHOLANGIO-PANCREATOGRAPHY) IN MILITARY HOSPITAL RAWALPINDI.
}

\footnotetext{
1. MBBS, FCPS Gastroenterology Assistant Professor Department of Gastroenterology Military Hospital Rawalpindi.

2. MBBS, FCPS Gastroenterology Department of Gastroenterology Military Hospital Rawalpindi.

3. MBBS, MD Gastroenterology Assistant Professor

Department of Gastroenterology NSMC, UOG, Gujrat.

4. MBBS, FCPS Gastroenterology Professor \& HOD Department of Gastroenterology, Military Hospital Rawalpindi.
}

Correspondence Address:

Dr. Irfan Younis

Department of Medicine

NSMC, UOG, Gujrat.

Irfanyounis7887@gmail.com

Article received on:

17/10/2016

Accepted for publication:

21/03/2019

Received after proof reading:

25/06/2019

\begin{abstract}
Adnan Qadir ${ }^{1}$, Maryum Khalid ${ }^{2}$, Irfan Younis ${ }^{3}$, Amjad Salamat ${ }^{4}$
\end{abstract}
ABSTRACT... To describe the indications, endoscopic findings and complications of Endoscopic retrograde cholangiopancreatography (ERCP) in a tertiary care hospital. Study Design: Retrospective analysis of data collected from all patients underwent ERCP in the year 2015. Setting: Gastroenterology department, Military Hospital Rawalpindi. Period: From $1^{\text {st }}$ January 2015 to $31^{\text {st }}$ December 2015. Materials and Methods: The main outcomes were technical success, safety and complications. Results: Total 469 patients underwent ERCP in military hospital Rawalpindi in year 2015. Common bile duct (CBD) cannulation was achieved in $437(93.1 \%)$ patients. CBD stones were found in $182(38 \%)$ and CBD stricture in $79(16.8 \%)$. Sphincteroplasty was needed for extraction of large stones in $13(2.7 \%)$ cases. CBD stricture with co-existing stones above was seen in 25 cases (5.3\%). Large stones not amenable to endoscopic extraction were seen in 24 cases $(5.1 \%)$. Total 25 cases of ampullary growth (5.3\%) and 15 cases $(3.1 \%)$ of CBD leak post cholecystectomy were noted. 6 cases $(1.27 \%)$ were identified as choledochal cyst with CBD Stones. PD stones with dilated PD identified in 5 cases $(1.06 \%)$ and post-cholecystectomy CBD clipped in 3 cases $(0.63 \%) .3$ cases of displaced PD stent ended up in successful retrieval. 21 cases developed acute pancreatitis (4.4\%) out of which 3 were found to have severe pancreatitis having fluid collections. 3 cases $(0.6 \%)$ had retroperitoneal perforation ( 2 were managed conservatively and 1 through surgery). 4 cases $(0.8 \%)$ had significant post procedure bleed requiring re-scope with adrenal injection at bleeding site, and hemostasis achieved. Conclusions: ERCP in Combined Military Hospital Rawalpindi hospital was associated with a high degree of technical success and a low risk of complications.

Key words: $\quad$ CBC, Complications, ERCP, Findings, Indications, Pancreatitis.

Article Citation: Qadir A, Khalid M, Younis I, Salamat A. Outcome of ERCP (endoscopic retrograde cholangio-pancreatography) in military hospital rawalpindi. Professional Med J 2019; 26(7):1062-1066.

DOI: 10.29309/TPMJ/2019.26.07.3767

\section{INTRODUCTION}

ERCP is technically demanding procedure carrying some procedure-associated risk as well. It actually combines the use of endoscope with X-ray imaging to examine the biliary and pancreatic ducts with the capability to intervene when indicated to treat the problems identified during procedure. ERCP was initially performed in 1968 mainly as a diagnostic modality; however it has evolved as a therapeutic procedure over the years. More than 500,000 ERCP procedures are performed per year in US with complication rate of $4 \%-10 \%$ and mortality rate between $0.05 \%-1 \%{ }^{1-}$ 6 , most common being Post ERCP pancreatitis, bleeding and infection. Infections after ERCP are usually due to combination of endoscopic and percutaneous procedures, poor biliary drainage, jaundiced patient and placement of stent in malignant strictures. ${ }^{7}$

Results of Post-ERCP complication are variable, in a 2-year prospective study from seventeen institutes included 2,347 patients, 9.8\% had post-ERCP complications, most common were pancreatitis (5.4\%) and hemorrhage (2\%). Nevertheless, acute pancreatitis has been found to be the most common and serious complication of ERCP. ${ }^{8}$ In this retrospective study the practice of ERCP is described over a period of one year with emphasis on outcome and frequency of complication related to this procedure.

The criteria for classification of complication used are given in the Table-l. 
Mild

Clinical evidence of bleeding (ie, not just endoscopic) Haemoglobin drop

Possible, or only very slight leak of fluid or contrast dye Treatable by fluids and suction for 3 days or less

Clinical pancreatitis: amylase at least thrice the upper limit of normal at more than $24 \mathrm{~h}$ after the procedure requiring admission or prolongation of planned admission to 2-3 days

Pancreatitis

Infection $>38^{\circ} \mathrm{C}$ at $24-48 \mathrm{~h}$
Moderate

Transfusion: 4 units or less No angiographic intervention or surgery

Any definite perforation treated medically for 4-10 days

.

Pancreatitis requiring

hospitalisation for 4-10 days

Febrile or septic illness requiring $>3$ days of hospital treatment or endoscopic or percutaneous intervention
Severe

Transfusion: 5 units or more or intervention (angiographic or surgical)

Medical treatment for more than 10 days or intervention (percutaneous or surgical)

Pancreatitis requiring hospitalisation for more than 10 days, or haemorrhagic pancreatitis, phlegmon or intervention (percutaneous drainage or surgery)

Septic shock or surgery

Table-I. Consensus criteria for ERCP complications

\section{METHODOLOGY}

\section{Study Design}

A retrospective cohort study was conducted at Gastroenterology department, Military Hospital Rawalpindi with the approval of hospital ethics committee. Informed consent was taken from all patients medical records were reviewed retrospectivelybytheauthor.Patientand procedure characteristics, as well as complications were recorded and entered into database Outcomes measured were 1) success rate of procedure, 2) frequency of different indications, 3) failure rate and 4) complication rate

Complication recorded included unplanned admissions; sedation-related events including pulmonary and cardiovascular events; infection; pancreatitis; bleeding; perforation; need for repeat endoscopic procedure or mortality within 30 days

\section{Statistical Analysis}

Data was collected on data sheets. For subsequent processing and analysis, the data was analyzed on Statistical Package for Social Sciences (SPSS) version 13 (Chicago, IL, USA). Mean and standard deviation were calculated for age and hospital stay.

\section{RESULTS}

\section{Demographic Characteristics}

Total 469 patients underwent ERCP in Military Hospital Rawalpindi in year 2015. Out of them $251(53 \%)$ were male and 218 (46\%) were female. A breakdown of patients from different age brackets is given in Table-II.

\begin{tabular}{|l|c|}
\hline $18-29$ years & $51(10.8 \%)$ \\
\hline $30-44$ years & $97(20.6 \%)$ \\
\hline $45-59$ years & $187(39.8)$ \\
\hline $\begin{array}{c}60 \text { years and above } \\
\text { Table-II. Breakdown of patients of different age } \\
\text { groups }\end{array}$ \\
\hline
\end{tabular}

\section{Procedure Characteristics}

Common bile duct (CBD) cannulation was achieved in 437 (93.1\%) patients. Out of these 311 patients (66\%) had CBD cannulation done directly. PD was cannulated first in other 77 patients (16\%) followed by CBD cannulation. Pancreatic de-roofing was done in 16 (3.4\%) and needle knife was needed in $27(5.7 \%)$ cases however, 10 out of these 27 procedures were not successful even after doing needle knife. Total 32 cases failed $(6.9 \%)$ majority of them having duodenum infiltrated with tumor.

Sphincteroplasty needed for extraction of large stones in $13(2.7 \%)$ cases. CBD stones were 
found in 182 (38\%) and CBD stricture in 79 (16.8\%). CBD strictures with co-existing stones above were seen in 25 cases (5.3\%). Large stone not amenable to endoscopic extraction was seen in 24 cases $(5.1 \%)$ as a result stent was placed to relieve obstruction in these patients. Total 25 cases of ampullary growth (5.3\%) and 15 cases (3.1\%) of CBD leak post cholecystectomy were noted. 6 cases (1.27\%) were identified as choledochal cyst with CBD Stones. PD stones with dilated PD identified in 5 cases (1.06\%) and post-cholecystectomy CBD clipped in 3 cases (0.63\%). 3 cases of displaced PD stent ended up in successful retrieval. A summary of these findings is given in the Table-III.

\begin{tabular}{|l|c|}
\hline \multicolumn{1}{|c|}{ Endoscopic Findings } & Percentages \\
\hline CBD Stones & $182(13 \%)$ \\
\hline CBD Stricture & $79(16.8 \%)$ \\
\hline CBD Stricture with co-existing stones & $25(5.3 \%)$ \\
\hline Large Stone & $24(5.1 \%)$ \\
\hline Ampullary Growth & $25(5.3 \%)$ \\
\hline CBD Leak Post Cholecystectomy & $15(3.1 \%)$ \\
\hline Choledochal Cyst & $6(1.27 \%)$ \\
\hline PD Stones & $5(1.06 \%)$ \\
\hline Post-cholecystectomy CBD Clipped & $3(0.63 \%)$ \\
\hline Displaced PD Stent & $3(0.63 \%)$ \\
\hline Table-III. Summary of frequency of findings and their \\
\hline \multicolumn{2}{|c|}{ percentages } \\
\hline
\end{tabular}

\section{Complications}

Post-ERCP acute pancreatitis was graded as mild, moderate or severe based upon hospital stay, 21cases developed acute pancreatitis (4.4\%) 18 with mild pancreatitis, 3 with severe pancreatitis having fluid collections. They were discharged after stay of few days in hospital. 3 cases $(0.6 \%)$ had retroperitoneal perforation out of which 2 were managed conservatively and 1 ended up in surgery. 4 cases $(0.8 \%)$ had significant post procedure bleed requiring rescope with adrenal injection at bleeding side and hemostasis achieved.

\section{DISCUSSION}

Most of procedures were successful (93\%). Biliary diseases were the most common indications for ERCP.

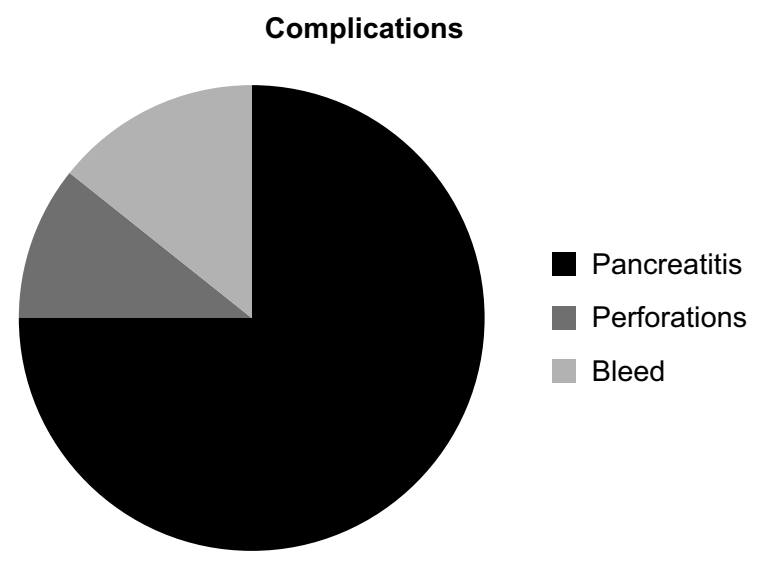

Among them CBD stones presenting as biliary colic, obstructive jaundice and less commonly as cholangitis were on top. Second commonest indication was the biliary stricture, both benign and malignant. The common malignancy encountered was the pancreatic cancer followed by cholangiocarcinoma. Other less common indications included ampullary growths and post surgical complication. Several studies and reviews have identified several risk factors. High complication rates were reported after interventional ERCP, especially with lengthy and extensive biliary or pancreatic manipulations, after which PEP rates can reach upto 30\%.9-10 Overall the procedures were complication free. Majority of the patients went home the same day they underwent the procedure. Commonest complaints were mild to moderated abdominal pain and bloating followed by pancreatitis. The reason for failure in incomplete procedure was the underlying disease malignancy causing the infiltration of peri-ampullary area and duodenum. In multiple studies female sex, younger, clinically suspected SOD, a past history of PEP were found to have high percentage of compliocations. ${ }^{11-12}$ Commonly risk factors for post ERCP complications include suspected sphincter of Oddi dysfunction, decompensated cirrhosis, problematic cannulation, percutaneous biliary access, younger patients, failed biliary drainage and pancreatic duct contrast injections. ${ }^{13,14}$ Severe post ERCP bleeding was reported in $0.1-0.5 \%$ of cases. ${ }^{15}$ Perforation of the pancreatic duct, bile duct or duodenum is notated in less than $1 \%$ of patients undergoing ERCP. ${ }^{16-17}$ Complications do 
occurred in subset of patients but majority were mild to moderate that didn't need any admission or intervention. One limitation of our study is that it is a retrospective review of data; as a result we were not able to prioritize variables and had to follow the already set pattern in procedures.

\section{CONCLUSION}

Overall ERCP is a safe procedure carried out on day-care basis, patients going home the same day in most of the cases. Success rate in big volume centers is above $90 \%$ and it is very effective mean to treat the underlying pathology hence ending the patient's suffering and misery. The most common indications for ERCP remain relief of biliary colic or cholangitis secondary to CBD stones. Complications of ERCP are less common. They are mild in majority needing no intervention and being managed conservatively. Copyright@ 21 Mar, 2019.

\section{REFERENCES}

1. Mazen Jamal M, Yoon EJ, Saadi A, Sy TY, Hashemzadeh $M$. Trends in the utilization of endoscopic retrograde cholangiopancreatography (ERCP) in the United States. Am J Gastroenterol 2007; 102:966-75.

2. Andriulli A, Loperfido S, Napolitano G, et al. Incidence rates of post-ERCP complications: A systematic survey of prospective studies. Am J Gastroenterol 2007; 102:1781-8.

3. Bodger K, Bowering K, Sarkar S, et al. All-cause mortality after first ERCP in England: Clinically guided analysis of hospital episode statistics with linkage to registry of death. GastrointestEndosc 2011; 74:825-33.

4. Christensen M, Matzen P, Schulze S, etal. Complications of ERCP: A prospective study. Gastrointest Endosc 2004; 60:721-31.

5. Cotton PB, Garrow DA, Gallagher J, et al. Risk factors for complications after ERCP: A multivariate analysis of 11,497 procedures over 12 years. Gastrointest Endosc 2009; 70:80-8.

6. Glomsaker T, Soreide K, Hoff G, et al. Contemporary use of endoscopic retrograde cholangiopancreatography (ERCP): A Norwegian prospective, multicenter study. Scand J Gastroenterol 2011; 46:1144-51.
7. Loperfido S, Angelini G, Benedetti G, et al. Major early complications from diagnostic and therapeutic ERCP: A prospective multicenter study. Gastrointest Endosc. 1998; 48(1):1-10.

8. Elmunzer BJ, Scheiman JM, Lehman GA, et al. A randomized trial of rectal indomethacin to prevent post-ERCP pancreatitis. N Engl J Med. 2012; 366(15):1414-22.

9. Pahk A, Rigaux J, Poreddy V, et al. Prophylactic pancreatic stents: Does size matter? A comparison of 4-Fr and 5-Fr stents in reference to post-ERCP pancreatitis and migration rate. Dig Dis Sci. 2011; 56(10):3058-64.

10. Cheng CL, Sherman S, Watkins JL, et al. Risk factors for post-ERCP pancreatitis: A prospective multicenter study. Am J Gastroenterol. 2006; 101(1):139-147.

11. Cheong YK, Bum K, Watkins JL, et al. Frequency and severity of post-ERCP pancreatitis correlated with the extent of pancreatic ductal opacification. Gastrointest Endosc. 2007; 65(3):385-398.

12. Freeman ML, Nelson DB, Sherman S, Haber GB, Herman ME, Dorsher PJ, et al. Complications of endoscopic biliary sphincterotomy. $\mathrm{N}$ Engl $\mathrm{J}$ Med 1996; 335:909-18.

13. Rabenstein T, Schneider HT, Hahn EG, Ell C. 25 years of endoscopic sphincterotomy in Erlangen: Assessment of the experience in 3498 patients. Endoscopy 1998; 30:A194-201.

14. Enns R, Eloubeidi MA, Mergener $\mathrm{K}$, et al. ERCP-related perforations: Risk factors and management. Endoscopy. 2002; 34(4):293-298.

15. Vandervoort J, Soetikno RM, Tham TC, et al. Risk factors for complications after performance of ERCP. Gastrointest Endosc. 2002; 56(5):652-656.

16. Fatima $J$, Baron $T H$, Topazian MD, et al. Pancreaticobiliary and duodenal perforations after periampullary endoscopic procedures: Diagnosis and management. Arch Surg. 2007; 142(5):448-455.

17. Freeman ML. Understanding risk factors and avoiding complications with endoscopic retrograde cholangiopancreatography. Curr Gastroenterol Rep 2003; 5:145-53. 


\begin{tabular}{|c|l|l|}
\hline \multicolumn{3}{|c|}{ AUTHORSHIP AND CONTRIBUTION DECLARATION } \\
\hline Sr. \# & Author-s Full Name & \multicolumn{1}{c|}{ Contribution to the paper } \\
\hline 1 & Adnan Qadir & Concept and design of study. \\
\hline 2 & Maryum Khalid & $\begin{array}{l}\text { Data collection Statistics, } \\
\text { Manuscript writing. } \\
\text { Critical revision of article, Drafting of } \\
\text { articles. } \\
\text { Critical revision of article, Concept } \\
\text { and design of study. }\end{array}$ \\
\hline 3 & Irfan Younis & Amjad Salamat \\
\hline
\end{tabular}

